\title{
Durability performance of fly ash based one-part geopolymer mortars ABDOLLAHNEJAD Z. ${ }^{1, a}$, PACHECO-TORGAL F. ${ }^{2, b}$, AGUIAR J.B. ${ }^{3, b}$ and JESUS C. ${ }^{4, C}$
}

\author{
${ }^{1}$ Civil Engineering Department, University of Minho, Guimarães, Portugal \\ ${ }^{2}$ C-TAC Research Centre, University of Minho, Guimarães, Portugal \\ atolumahvash@gmail.com, ${ }^{\mathrm{b}}$ torgal@civil.uminho.pt, ${ }^{\mathrm{c}}$ aguiar@civil.uminho.pt, \\ dcjesus@civil.uminho.pt
}

Keywords: Portland cement, one part geopolymer, hybrid alkaline, mortars, durability

\begin{abstract}
Environmental concerns regarding the high $\mathrm{CO}_{2}$ emissions related to the production of ordinary Portland cement (OPC) led to research efforts on the development of eco-efficient alternative binders. Geopolymers constitute promising inorganic binders alternative to OPC which are based on aluminosilicates by-products and alkali activators. The geopolymerization technology of aluminosilicates is a complex chemical process evolving dissolution of raw materials, transportation, orientation and polycondensation of the reaction products. Classical two part geopolymers could become more eco-efficient with a lower $\mathrm{CO}_{2}$ footprint if sodium silicate usage is avoided. Besides current geopolymeric mixes can suffer from efflorescence originated by the fact that alkaline or soluble silicates that are added during processing cannot be totally consumed during geopolymerisation. Therefore, new and improved geopolymer mixes are needed. One-part geopolymers (sodium silicate free) were first proposed in 2007. However, very few papers were published on these materials. This paper presents experimental results on the durability performance of one-part geopolymers concerning water absorption, penetration of chloride, carbonation resistance and resistance to acid attack. Hydration products results assessed by FTIR spectra are also presented.
\end{abstract}

\section{Introduction}

Concrete is the most used construction material on Earth, its consumption reaching almost 10.000 million tons per year and the projections for the global demand of the main binder of concrete structures, Portland cement, show that in the next 40 years, concrete production will keep on rising [1].

Portland cement production represents $74-81 \%$ of the total $\mathrm{CO}_{2}$ emissions of concrete, aggregates, in turn, represent $13-20 \%$ of the total, therefore batching, transport and placement activities have no relevant expression in terms of carbon dioxide emissions [2,3].

The production of one tonne of Portland cement generates 0.55 tonnes of chemical $\mathrm{CO} 2$ and requires an additional 0.39 tonnes of $\mathrm{CO}_{2}$ in fuel emissions for baking and grinding, all accounting for a total of 0.94 tonnes of $\mathrm{CO}_{2}$ [4]. In order to reduce the environmental impacts associated to OPC some solutions have been suggested by Flatt et al. [5]:

1. Partial cement (clinker) replacement by supplementary cementitious materials

2. Development of alternative binders

3. Broader use of concrete mix designs that limit cement content

4. Recycling of demolished concrete in new concretes

5. Enhancement of durability (designing new infrastructures for longer service life)

6. Rehabilitation of existing infrastructures (extending the service life of existing infrastructures)

Concerning the development of alternative binder geopolymers have received a lot of attention in the last decade. The name 'geopolymer' was introduced by Davidovits in the 1970s, however the technology of alkali-activation predates this terminology by more than 60 years [6]. 
These materials "are produced through the reaction of an aluminosilicate-normally supplied in powder form as an industrial by-product or other inexpensive material - with an alkaline activator, which is usually a concentrated aqueous solution of alkali hydroxide, silicate, carbonate or sulphate" [6].

Despite all the investigations published on these materials in the last decades some aspects still needed to be further investigated especially concerning durability performance [7]. The discovery of one-part geopolymers (also known as hybrid alkaline cements) is considered a key event on the evolution of low carbon geopolymer technology, however they were associated with very low compressive strength [8]. According to those authors an increase in the compressive strength to $4 \mathrm{MPa}$ would require $24 \mathrm{~h}$ hydrothermal treatment at $100{ }^{\circ} \mathrm{C}$. The use of a much more intensive treatment $\left(140{ }^{\circ} \mathrm{C}\right)$ would increase compressive strength to 12-20 MPa. Some authors recently investigated these materials having reported a 28 days curing compressive strength of $27 \mathrm{MPa}$ by using fly ash and 30\% OPC [9]. This paper presents results on the durability of these new mixtures.

\section{Introduction}

Materials and mix proportioning. The compositions of the dry mixes contain the following materials: kaolin, fly ash, ordinary Portland cement (OPC), sodium hydroxide, calcium hydroxide $\left(\mathrm{Ca}(\mathrm{OH})_{2}\right)$, water and superplasticizer. These are adapted from the ones presented in the international patent WO 2007/109862 A1 [10]. The OPC is of class I $42.5 \mathrm{R}$ type, containing between $95 \%$ to $100 \%$ of clinker content, a specific weight of $3.15 \mathrm{~g} / \mathrm{cm}^{3}$ and a Blaine fineness of $3842 \mathrm{~cm}^{2} / \mathrm{g}$. A superplasticizer (SP) from SIKA $3002 \mathrm{HE}$ was used to maintain a uniform consistency throughout the different mixes. Fly ash was used as partial replacement of Portland cement. Its chemical composition complies with the minimum requirements indicated in EN-450-1 [11] being categorized as class $\mathrm{B}$ and group $\mathrm{N}$ for the loss of ignition and fineness, respectively. It has a specific weight of $2.42 \mathrm{~g} / \mathrm{cm}^{3}$. A mixture of kaolin and sodium hydroxide with is calcined in a furnace at $650{ }^{\circ} \mathrm{C}$ during 140 minutes. The cooled mixture was grinded into poder and named as calcined stuff. Table 1 shows the composition of the five mixtures which were tested in this study.

Table 1: Mix composition $\left[\mathrm{Kg} / \mathrm{m}^{3}\right]$

\begin{tabular}{|l|c|c|c|c|c|c|c|}
\hline \multicolumn{1}{|c|}{ Name } & OPC & Fly ash & $\mathrm{Ca}(\mathrm{OH})_{2}$ & Calcined stuff & Water & SP & Sand \\
\hline R1 - OPC 100 & 1013.8 & ---- & ---- & ---- & 354.8 & 8.1 & 811 \\
\hline R2 - OPC 70 - FL 30 & 689.6 & 295.5 & --- & ---- & 344.8 & 7.8 & 788.1 \\
\hline R3 - OPC 30-FL 58.3-CH 7.7-CS 4 & 283.9 & 551.7 & 32.9 & 37.8 & 331.2 & 7.5 & 757 \\
\hline R4 - OPC 26-FL 58.3-CH 7.7-CS 8 & 245 & 549.5 & 32.8 & 75.4 & 329.9 & 7.5 & 754 \\
\hline R 5 - OPC 18-FL 58.3-CH 7.7-CS 16 & 168.3 & 545.2 & 32.5 & 149.6 & 327.3 & 7.4 & 748.1 \\
\hline
\end{tabular}

Testing. The compressive strength was performed under NP EN 206-1. The mortar specimens were conditioned at a temperature equal to $21 \pm 2{ }^{\circ} \mathrm{C}$ cured in a moist chamber until they have reached the testing ages. Tests were performed on $50 \times 50 \times 50 \mathrm{~mm}^{3}$ specimens. Compressive strength for each mixture was obtained from an average of 3 cubic specimens determined at the age of 14 and 28 days of curing.

Concerning water absorption by immersion specimens with 28 days curing were immersed in water at room temperature for 24 hours. First the weight of the specimens while suspended by a thin wire and completely submerged in water is recorded as $\mathrm{W}_{\mathrm{Im}}$ (Immersed weight). After that the specimens were removed from water, and placed for $1 \mathrm{~min}$ on a wire mesh allowing water to drain, then visible surface water is removed with a damp cloth and weight is recorded as $\mathrm{W}_{\text {Sat }}$ (Saturated weight). All specimens are placed in a ventilated oven at $105{ }^{\circ} \mathrm{C}$ for not less than 24 hours and allowing that two successive weightings at intervals of 2 hours show an increment of loss not greater than $0,1 \%$ of the last previously determined weight of the specimen. The weight of the dried specimens is recorded as $\mathrm{W}_{\text {Dry }}$ (oven-dry weight).

The water absorption by capillarity test was done according to EN 1015-18:2002 using three specimens with $100 \times 100 \times 100 \mathrm{~mm}^{3}$. After been dried in the oven at $105{ }^{\circ} \mathrm{C}$ during 60 hours, they 
were isolated along their lateral surfaces with a fine layer of silicon in order to reduce water evaporation.

The chloride ion diffusion coefficient was carried out following the standard LNEC 463. In this test the penetration depth of chloride ions through $50 \mathrm{~mm}$ thick cylindrical slices $(100 \mathrm{~mm}$ nominal diameter) with 28 days of curing is assessed. A potential electric difference of $30 \pm 0.2 \mathrm{~V}$ is maintained across the specimens. One face is immersed in a solution with sodium chloride and sodium hydroxide, and the other in a sodium hydroxide solution. After the migration of chloride ions the penetration depth is measured by splitting the specimens. The surface of the split mortar is then spread with silver nitrate $\left(\mathrm{NO}_{3} \mathrm{Ig}\right)$ solution and the penetration depth is measured by difference in the colour. The chloride diffusion coefficient can be calculated using the following equation:

$$
\text { Dnssm }=\frac{0.0239(273+T) L}{(U-2) t}\left(x_{d}-0.0238 \sqrt{\frac{(273+T) L x_{d}}{U-2}}\right)
$$

Where Dnssm is non-steady-state migration coefficient, $\times 10-12 \mathrm{~m} 2 / \mathrm{s}$; U: absolute value of the applied voltage $(\mathrm{V})$; $\mathrm{T}$ : average value of the initial and final temperature in the anolyte solution $\left({ }^{\circ} \mathrm{C}\right)$; L: Thickness of the specimen $(\mathrm{mm}) ; \mathrm{X}_{\mathrm{d}}$ : Average value of the penetration depth $(\mathrm{mm})$.

The carbonation resistance test was performed with the following conditions of temperature, relative humidity ( $\mathrm{RH}$ ) and $\mathrm{CO}_{2}$ concentration: $20^{\circ} \mathrm{C}, 55 \%$ and $4 \%$, respectively. The specimens were taken out of the carbonation chamber and split in a tensile test. The split surfaces were cleaned and sprayed with a phenolphthalein $\mathrm{pH}$ indicator. The indicator used was a phenolphthalein $1 \%$ ethanol solution with $1 \mathrm{~g}$ phenolphthalein and $90 \mathrm{ml} 95.0 \mathrm{~V} / \mathrm{V} \%$ ethanol diluted in water to $100 \mathrm{ml}$. In the noncarbonated part of the specimen, where the mortar was still highly alkaline, a purple-red colour was obtained. In the carbonated part of the specimen where the alkalinity of mortar is reduced, no coloration occurred. The average depth of the colourless phenolphthalein region was measured in twenty points, perpendicular to the two edges of the split face.

The resistance to acid attack was carried out using cubic specimens with $50 \times 50 \times 50 \mathrm{~mm}^{3}$. Before being immersed in a solution containing $10 \%$ sulphuric acid $\left(\mathrm{H}_{2} \mathrm{SO}_{4}\right)$ the weight of the specimens were assessed. The weights of specimens were assessed again after 7, 14, 28 and 56 days after immersion in the acid solution. The appearances of specimens were also observed.

The FTIR spectra were acquired in the attenuated total reflectance mode (ATR), between 4000 and $550 \mathrm{~cm}^{-1}$, using a Perkin Elmer FTIR Spectrum BX with an ATR PIKE MIRacle Specimens for FTIR study were prepared by mixing $1 \mathrm{mg}$ of sample in $100 \mathrm{mg}$ of $\mathrm{KBr}$ as .suggested by Zhang et al. [12]. Spectral analysis was performed over the range $4000-400 \mathrm{~cm}^{-1}$ at a resolution of $4 \mathrm{~cm}^{-1}$.

\section{Results and discussion}

Compressive strength. Fig. 1 shows the compressive strength results. The reduction of OPC content leads to a high reduction on the compressive strength of the mortars. The slow hydration characteristics of fly ash contribute to explain that reduction. The mixture with just $30 \%$ OPC (and 58.3 fly ash, 7.7 calcium hydroxide and $4 \%$ calcined stuff) shows an almost $40 \%$ reduction in compressive strength when compare to the reference mixture. Since this mixture has a higher percentage reduction on OPC content this could mean that the addition of metakaolin and calcined sodium hydroxide could have compensated that reduction. However, the use of increase content in calcined stuff does not seem to compensate the OPC reduction. Thus meaning that the use of $4 \%$ calcined stuff seems to be an optimum content. 


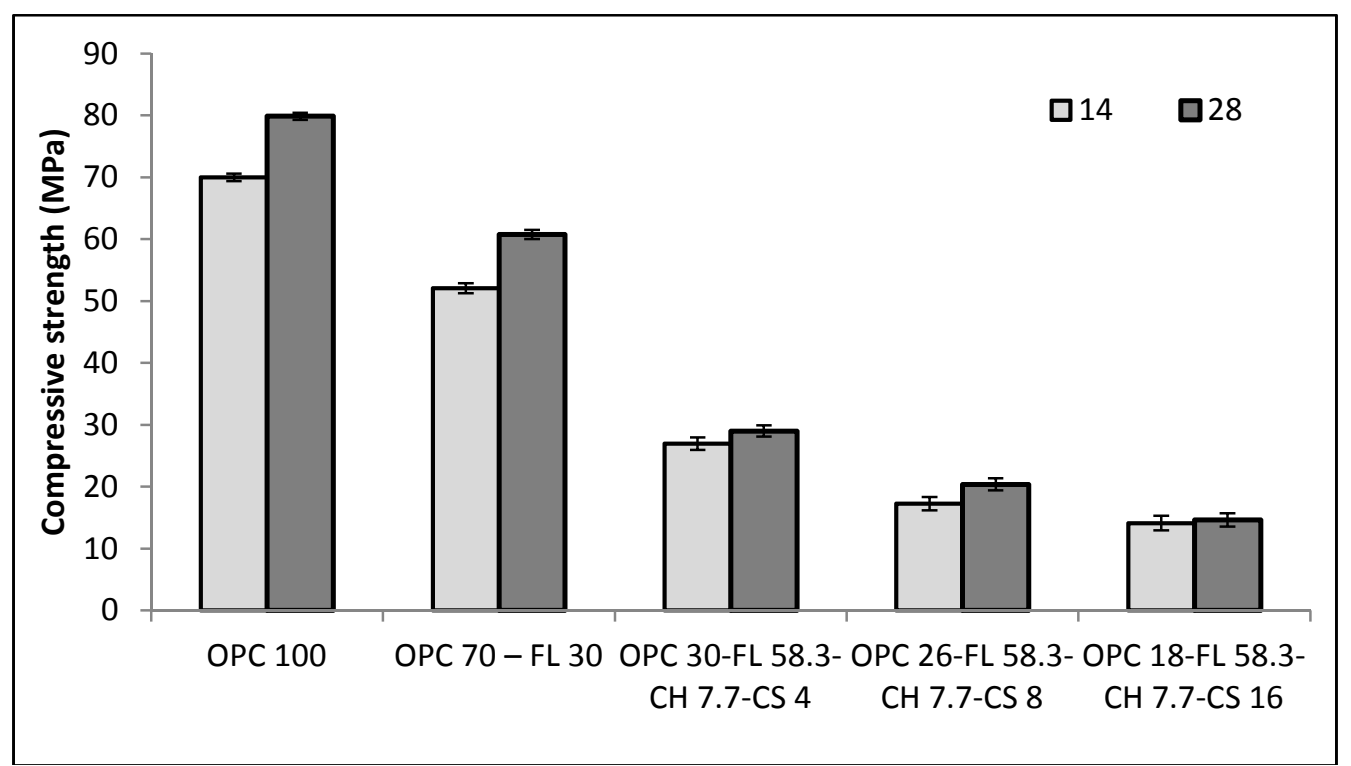

Fig 1. Compressive strength

Water absorption by immersion. The results of water absorption by immersion are presented in Fig. 2. Since all the mixtures have the same w/b ratio they should present a similar open porosity. So the differences between the several mixtures could be explained by the scatter data because they are small enough for that. Of course the different hydration products present in the different mixtures may contribute for the porosity differences but only in a very slight manner. That's why the mixture already mention in the previous section as having a good compressive strength performance shows the lower open porosity.

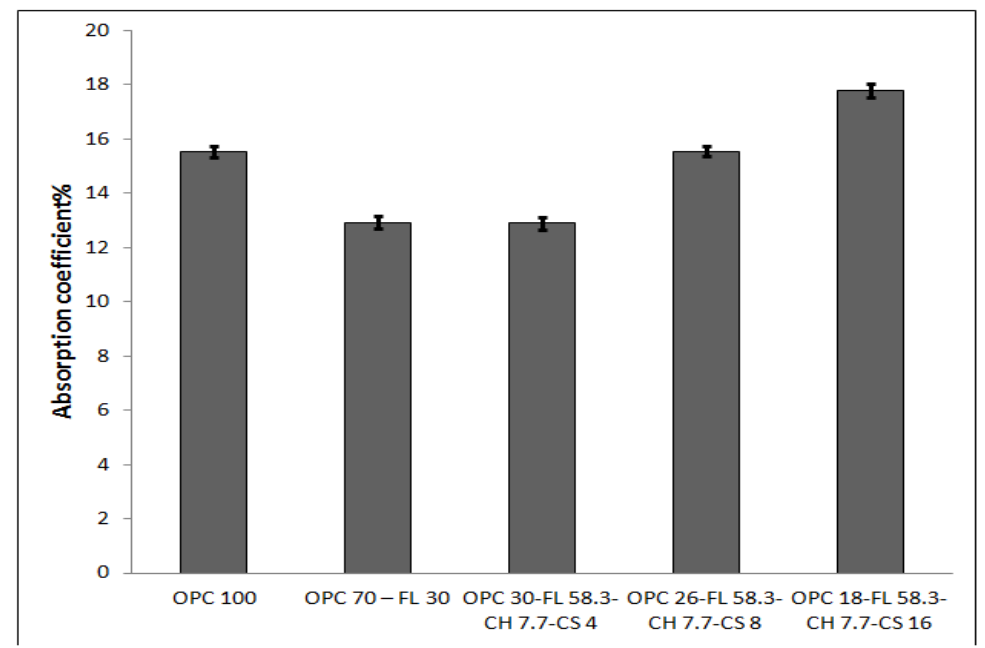

Fig 2. Water absorption by immersion

Capillarity water absorption. The water absorption capillarity coefficients are showed in Fig. 3. The reference mixture shows the best performance of them all. On the opposite side the mixture with 26\% OPC 58.3 fly ash, 7.7 calcium hydroxide and $8 \%$ calcined stuff clearly shows a very high water absorption by capillarity even at early ages. Such performance is typical of a microstructure with a high amount of capillary pores. The three remaining mixtures show a similar capillary water absorption coefficient indicating a similar internal capillary pore network. 


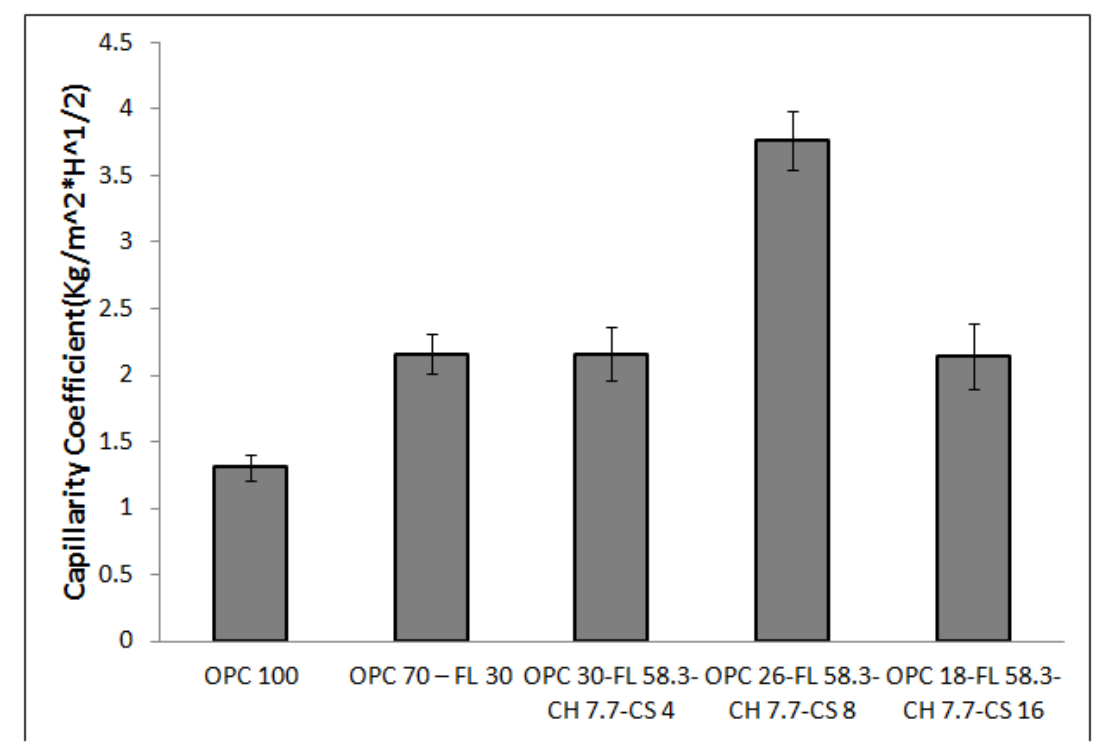

Fig 3. Water absorption capillarity coefficient.

Chloride diffusion. Fig. 4 shows the results of the chloride diffusion coefficient. The results are in accordance with the water absorption (open porosity) results. They show that all the mixtures have in the worst case a moderate resistance to chloride diffusion when a comparison is made to the performance of Table 2. With the exception of the mixture with 18\% OPC 58.3 fly ash, 7.7 calcium hydroxide and $16 \%$ calcined stuff all the other three mixtures in which OPC was partially replaced by fly ash showed a high resistance to chloride diffusion.

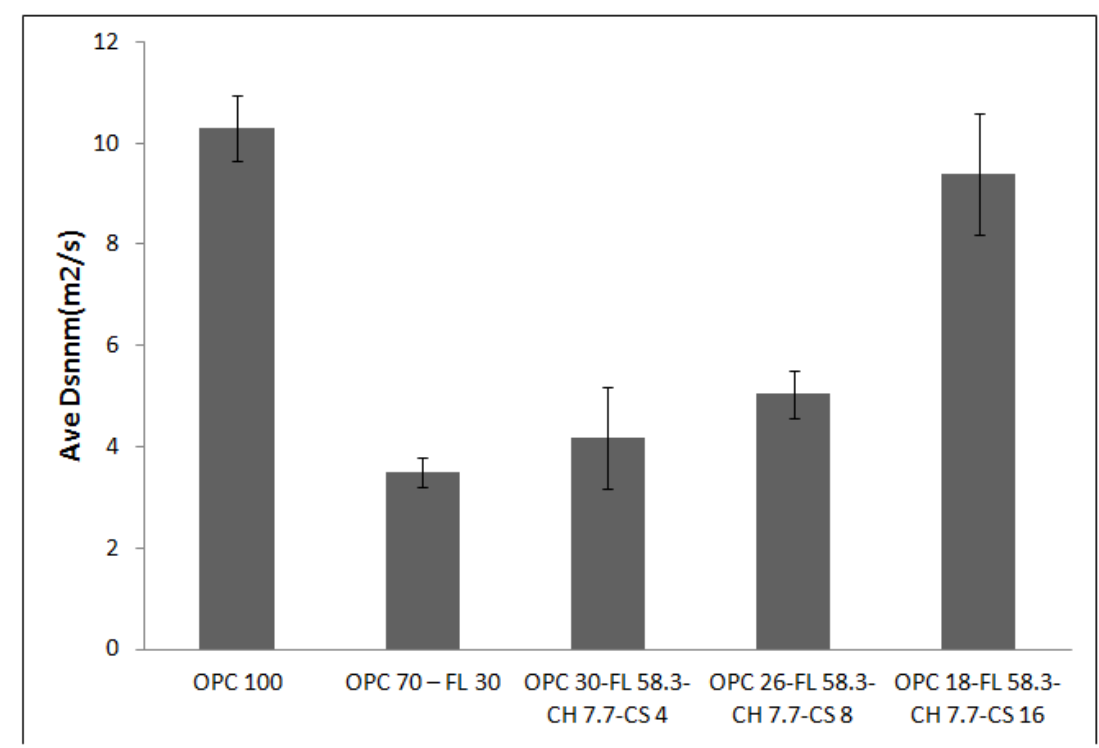

Fig 4. Chloride diffusion coefficient

Table 2 - Resistance to chloride penetration [13]

\begin{tabular}{|c|c|}
\hline$\times 10^{-12}\left(\mathrm{~m}^{2} / \mathrm{s}\right)$ & Concrete resistance \\
\hline$>15$ & Low \\
\hline $10-15$ & Moderate \\
\hline $5-10$ & High \\
\hline $2.5-5$ & Very high \\
\hline$<2.5$ & Ultra high \\
\hline
\end{tabular}

Carbonation resistance. Fig. 5 shows the results of the carbonation resistance. The $100 \%$ OPC based mortar showed the lowest carbonation depth. Replacing 30\% OPC by fly ash leads to a 
higher carbonation depth. Part of the explanation is related to the higher capillarity coefficient of the latter and the other part to the different hydration products.

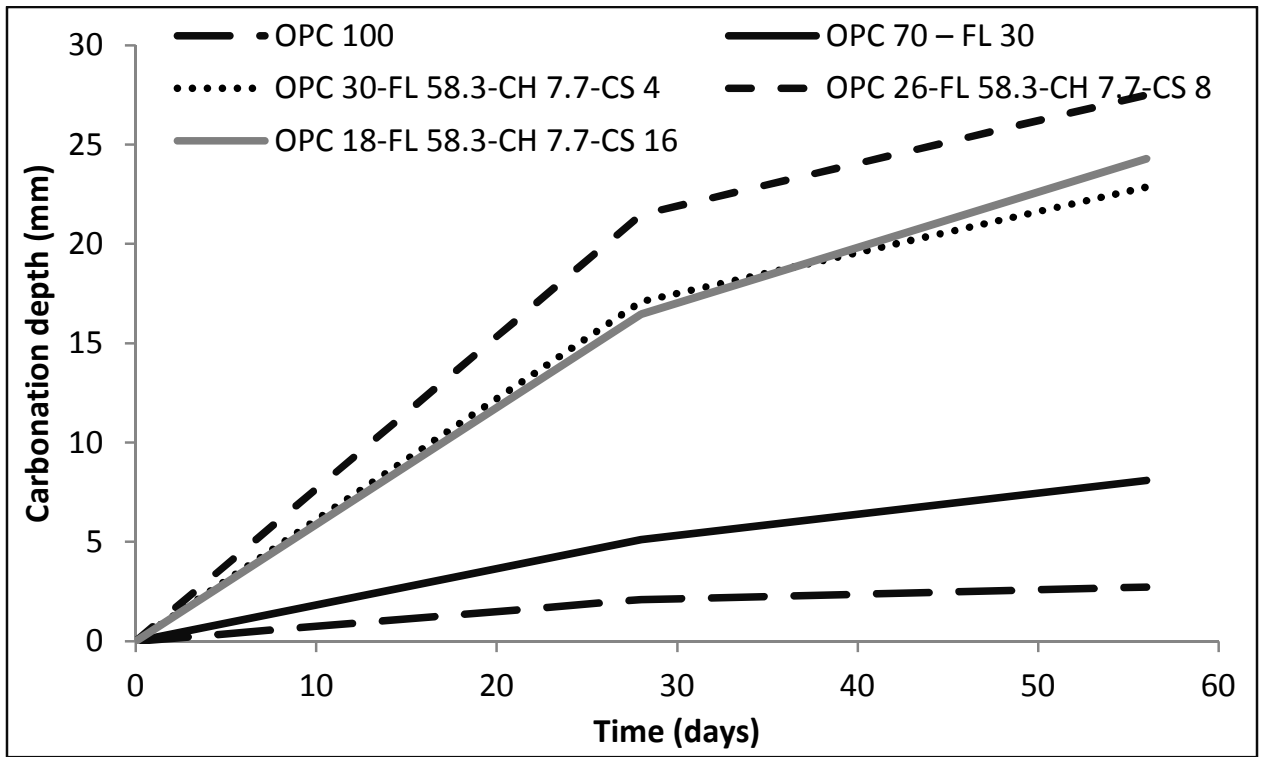

Fig 5. Carbonation depth

Previous investigations [14] have already reported an increase in concrete carbonation when flyash (FA) is used. The mixture with $30 \%$ OPC, $58.3 \mathrm{FA}, 4 \%$ calcined stuff and $7.7 \% \mathrm{Ca}(\mathrm{OH})_{2}$ shows a much higher carbonation depth than the second mixture with $30 \%$ FA. Since both mixtures have the same capillarity coefficient this means that the carbonation behaviour is related exclusively to the different hydration products. Thus meaning that the new hydration products are proper to carbonation. As to the mixture with $26 \%$ OPC, $58.3 \mathrm{FA}, 8 \%$ calcined stuff and $7.7 \% \mathrm{Ca}(\mathrm{OH})_{2}$ it shows the highest carbonation depth. This result is not a surprise because this mixture has also the highest water absorption capillarity. The mixture with 18\% OPC, $58.3 \mathrm{FA}, 16 \%$ calcined stuff and $7.7 \% \mathrm{Ca}(\mathrm{OH})_{2}$ shows almost the same carbonation depth as the mixture with $30 \% \mathrm{OPC}$ and just $4 \%$ calcined stuff meaning that difference has little influence on carbonation depth.

Resistance to acid attack. The results of mass loss for specimens exposed to $10 \%$ sulphuric acid solutions are shown in Fig 6.

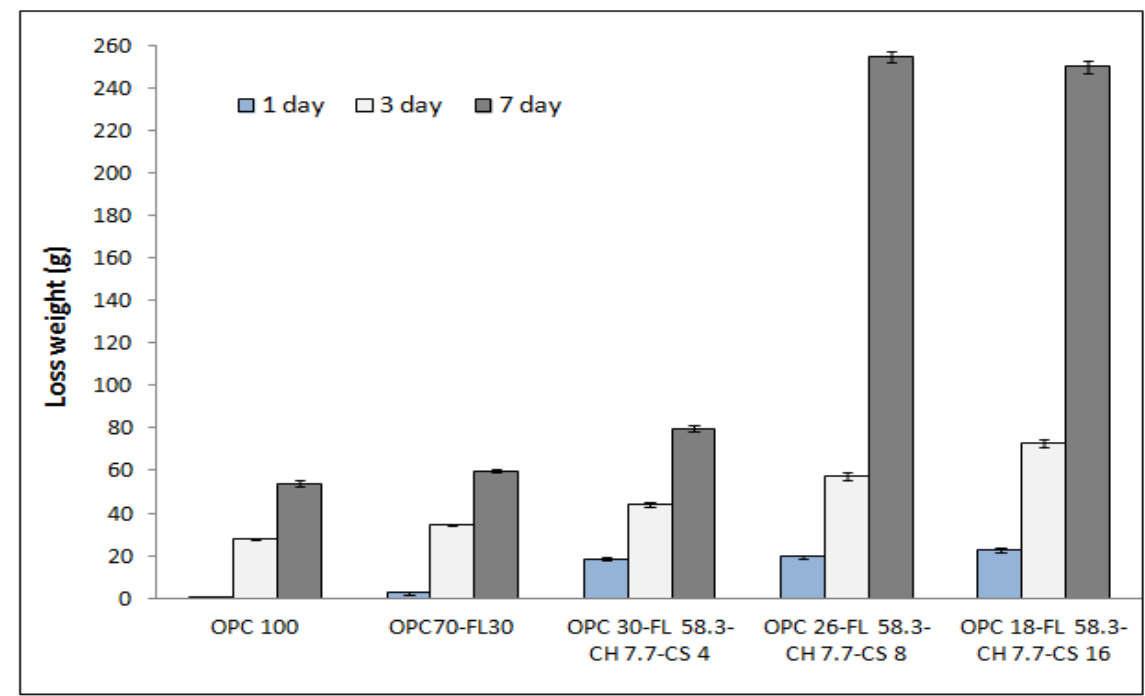

Fig 6. Weight loss of specimens due to acid attack 
After 1 day the best results are shown by the reference mixture and also by the mixture in which $30 \%$ OPC was replaced by fly ash. Since the reference mixture has much lower capillary water absorption than the other mixes this means that in a short term the rate of acid ingress contributes to explain the observed results. However, this is not the case of the one part geopolymeric mixture with $8 \%$ calcined stuff because since it has the highest capillarity coefficient it should have a higher weigth loss than the other geopolymeric mixtures.

After 3 days exposure to acid attack one can confirm that the weigth loss is proportional to the OPC content in the mixtures. A higher OPC content is associated to a lower weight loss. High pozzolan content mixtures showed lower resistance to acid attack this results do not confirm previous findings about the fact that the presence of pozzolanic admixtures was found to lower the detrimental effect of acid attack on concrete $[15,16]$. Probably because a denser microstructure typical of pozzolanic based mixtures were not yet formed by the time this mixtures were tested.

FTIR. The FTIR spectra are presented in Fig. 7. The strong peak band $965 \mathrm{~cm}^{-1}$ is characterized as asymmetric Si-O-Si or Al-O-Si stretching, which is typical of the polymerization of the silicate group with the formation of $\mathrm{CSH}[17,18]$. A shift to a high wave number occurs when the different spectra are compared. Usually this indicates an increase in the Si content of the gel.

The carbonate bands C-O at around $1415 \mathrm{~cm}^{-1}$ and $850 \mathrm{~cm}^{-1}$ arise from the reactions of atmospheric $\mathrm{CO}_{2}$ with calcium hydroxide. This peak intensity changes with the amount of calcium hydroxide.

The broad bands in the region of $1648-3000 \mathrm{~cm}^{-1}$ characterized the spectrum of stretching and deformation vibrations of $\mathrm{O}-\mathrm{H}$ and $\mathrm{H}-\mathrm{O}-\mathrm{H}$ groups from the weakly bound water molecules.

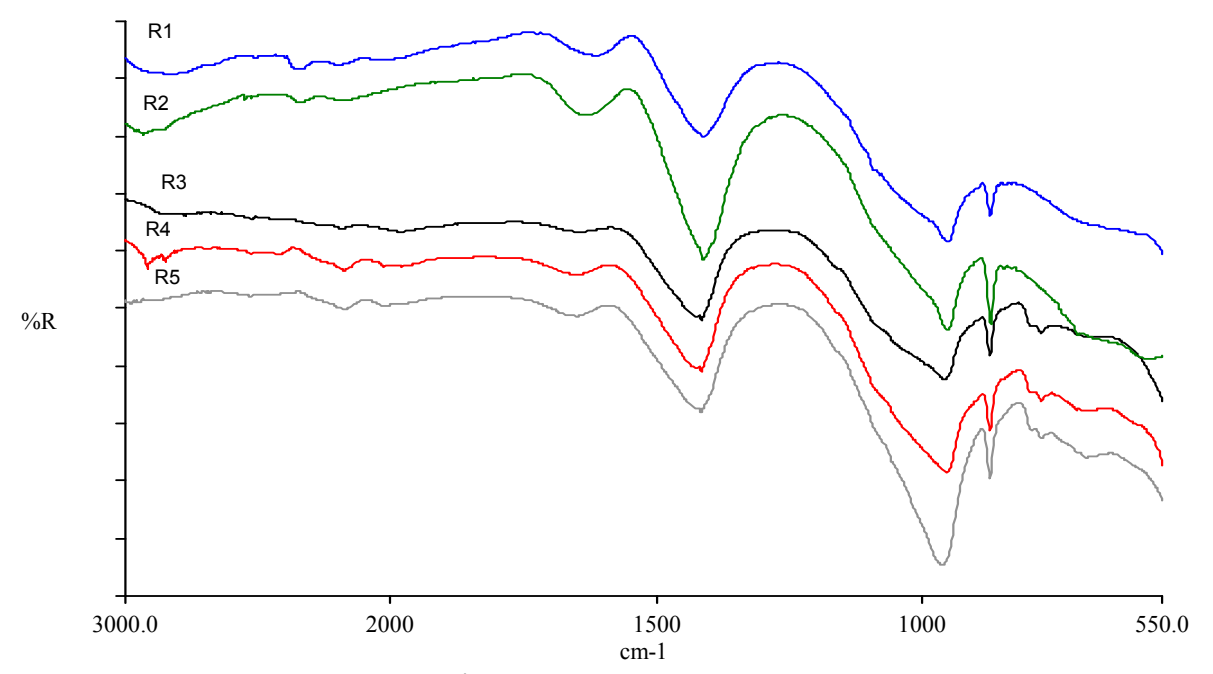

Fig 7. FTIR spectra

\section{Conclusions}

In this study, the durability of OPC mortars and one part geopolymer mortars were assessed using three different tests (water absorption by immersion, water absorption by capillarity and resistance to acid attack). Compressive strength results were also presented showing that the reduction of OPC content in the mortars leads to a high reduction on the compressive strength. The slow hydration characteristics of fly ash leads to a severe reduction on mechanical strength. In the geopolymeric mixtures the one with of $4 \%$ calcined stuff seems to correspond to a good compromise between a low OPC content and an acceptable compressive strength. The results of water absorption by immersion are very similar for all the mixtures which is due to the fact that they have the same $\mathrm{w} / \mathrm{b}$ ratio. The capillary water absorption is very high for the one part geopolymeric mixtures with $8 \%$ calcined stuff indicating a microstructure with very high amount of capillary pores. The results of resistance to acid attack show that the weight loss is proportional to the OPC content in the mixtures. 


\section{References}

[1] F. Pacheco-Torgal, J.A. Labrincha, S. Jalali, V.M. John, Eco-efficient concrete. Woodhead Publishing Limited Abington Hall, Cambridge, 2013

[2] D. Flower, J. Sanjayan, Green house gas emissions due to concrete manufacture, International Journal of Life Cycle Assessment 12 (2007) 282-288.

[3] D. Huntzinger, T. Eatmon, A life-cycle assessment of Portland cement manufacturing: comparing the traditional process with alternative technologies, Journal of Cleaner Production 17 (2009) 668-675.

[4] E. Gartner, Industrially interesting approaches to low- $\mathrm{CO}_{2}$ cements, Journal of Cement and Concrete Research 34 (2004)1489-1498.

[5] R. Flatt, R. Roussel, C.R. Cheeseman, Concrete: An eco-material that needs to be improved, Journal of the European Ceramic Society 32 (2012) 2787-2798.

[6] J.L. Provis, Geopolymers and other alkali activated materials: why, how, and what ? Journal of Materials and Structures 47 (2014) 11-25.

[7] F. Pacheco-Torgal, Z. Abdollahnejad, A.F. Camões, M. Jamshidi, Y. Ding, Durability of alkaliactivated binders. A clear advantage over Portland cement or an unproven issue ? Journal of Construction and Building Materials 30 (2012) 400-405.

[8] D. Kolousek, J. Brus, M. Urbanova, J. Andertova, V. Hulinsky, J. Vorel, Preparation, structure and hydrothermal stability of alternative (sodium silicate-free) geopolymers, Journal of Materials Science 42 (2007) 9267-9275.

[9] Z. Abdollahnejad, P. Hlavacek, S. Miraldo, F. Pacheco-Torgal, A. Aguiar, Compressive strength, microstructure and hydration products of hybrid alkaline cements, Journal of Materials Research (in press, 2014)

[10] D. Zheng, J.S.J. Van Deventer, P. Duxson, The dry mix cement composition, methods and systems involving same. International Patent WO 2007/109862 A1, 2007.

[11] NP EN 450-1, Fly ash for concrete - Part 1: Definition, specifications and conformity criteria.

[12] M. Zhang, B. Wruck, B.; A. Graeme - Barber, E. Salje, M. Carpenter, Phonon-spectroscopy on alkali-feldspar: phase transitions and solid solutions, American Mineralogist 81 (1996) 92-104.

[13] O.E. Gjørv, Performance and serviceability of concrete structures in the marine environment", Proceedings, Odd E. Gjørv Symposium on Concrete for Marine Structures, Ed. por P.K. Mehta, CANMET/ACI, 259-279, 1996.

[14] K. Khunthongkeaw, S. Tangtermsirikul, T. Leelawat, A study on carbonation depth prediction for fly ash concrete, Journal of Construction and Building Materials 20 (1996) 744-753

[15] R.E. Beddoe, K. Schmidt, Acid attack on concrete - effect of concrete composition. Part 1. Cem Int 2009;7:88-94.

[16] S. Goyal, M. Kumar, D.S. Sidhu, B. Bhattacharjee, Resistance of mineral admixture concrete to acid attack. J Adv Concr Technol 7 (2009) 273-83.

[17] I. Garcia Lodeiro, A. Fernandez-Jimenez, M.T. Blanco, A. Palomo, FTIR study of sol-gel synthesis of cementitious gels: CSH and NASH. J Sol-Gel Sci Technol 45 (2008) 63-72.

[18] I. Garcia Lodeiro, D. Macphee, A. Palomo, A. Fernandez-Jimenez, Effect of alkalis on fresh CSH gels. FTIR analysis. Cem Concr Res 39 (2009) 147-53. 